\title{
EVALUACIÓN DE LA CALIDAD DE UN ABONO LÍQUIDO PRODUCIDO VÍA FERMENTACIÓN HOMOLÁCTICA DE HECES DE ALPACA
}

\section{QUALITY ASSESMENT OF A LIQUID FERTILIZER PRODUCED THROUGH HOMOLACTATE FERMENTATION FROM ALPACA FAECES}

\author{
Henrry Quiñones Ramirez ${ }^{1}$, Wilder Trejo Cadillo² y Juan Juscamaita Morales ${ }^{3}$
}

\begin{abstract}
Resumen
El alto costo económico y ambiental por el uso de fertilizantes sintéticos conlleva a la búsqueda de alternativas más viables y sostenibles (Pindi, 2012). En este estudio se tuvo como objetivo evaluar la calidad nutricional, carga bacteriana enteropatógena y la fitotoxicidad de un abono líquido producido a partir de heces de alpaca, mediante el proceso biotecnológico de fermentación homoláctica. Veinticinco tratamientos por triplicado fueron preparados con heces de alpaca, lactosuero, melaza y un consorcio microbiano ácido láctico (B-Lac) en diferentes proporciones. Se determinó el tratamiento más ácido al quinto día de fermentación utilizando un diseño completo al azar con arreglo factorial $5 x 5$ (B-Lac y melaza: 0\%, 5\%, 10\%, 15\% y 20\% de cada factor), realizando un análisis de varianza y la Prueba de Tukey $(\mathrm{p}<0.05)$ mediante la aplicación del software $\mathrm{SAS}^{\circledR}$ versión 8.0. El tratamiento elegido contiene heces de alpaca, lactosuero, melaza y B-Lac en proporción 40: 40: 15: 5, respectivamente; existiendo efecto de interacción entre ambos factores ( $\mathrm{p}=$ 0.0025). El efluente líquido fue denominado Alpa-biol ( $\mathrm{pH}=3.83$; C.E. $\left.=23.4 \mathrm{dS} \cdot \mathrm{m}^{-1}\right)$, cuya dilución al $0.1 \%$ resulta óptimo para su uso en campo. Los análisis de laboratorio indican un alto contenido nutricional en su forma pura; bajos niveles de cadmio, plomo y cromo; y ausencia de coliformes totales, coliformes fecales y E. coli. Siendo el Alpa-biol un abono de alta calidad nutricional y microbiológica se recomienda difundir su uso en los agro-ecosistemas altoandinos.
\end{abstract}

Palabras clave: Calidad, abono líquido, fermentación homoláctica, heces de alpaca.

\begin{abstract}
The high economic and environmental cost of the use of synthetic fertilizers leads to the search of more viable and sustainable alternatives (Pindi, 2012). This study was aimed at assessing the nutritional quality, enteropathogenic bacterial load and the phytotoxicity of a liquid fertilizer produced from alpaca faeces through the biotechnological process of homolactate fermentation. Twenty-five treatments in triplicate were prepared with alpaca faeces, lactoserum, molasses and a lactic acid microbial consortium (B-Lac) in different ratios. The most acid treatment was determined on the fifth day of fermentation using a completely randomized design with a $5 x 5$ factorial arrangement (B-Lac and molasses: $0 \%, 5 \%, 10 \%, 15 \%$ and $20 \%$ of each factor), by carrying out an analysis of variance and Tukey's test $(\mathrm{p}<0.05)$ through the application of the SAS ${ }^{\circledR}$ software version 8.0. The chosen treatment contains alpaca faeces, lactoserum, molasses and B-Lac in ratios of 40: 40: 15: 5, respectively; with an interaction effect between both factors $(p=0.0025)$. The liquid effluent was named Alpa-biol $\left(\mathrm{pH}=3.83\right.$; C.E. $\left.=23.4 \mathrm{dS} \cdot \mathrm{m}^{-1}\right)$, whose dilution at $0.1 \%$ is optimum for field use. Laboratory analysis point out a high nutritional content in its pure form, low levels of cadmium, lead and chromium; and the absence of total coliforms, fecal coliforms and E. coli. Alpabiol is a fertilizer of high nutritional and microbiological quality, and its use is recommended in high-Andean agro-ecosystems.
\end{abstract}

Key words: Quality, liquid fertilizer, homolactate fermentation, alpaca faeces.

\section{Introducción.}

En el Perú más de 500000 familias altoandinas dependen de la crianza de alpacas (Fernández, 1991) que alcanza una población estimada de 4800000 ejemplares, equivalente al $87 \%$ del total mundial (UNIDO, 2006). Un recurso adicional de su explotación son las heces, las cuales son aprovechadas como combustible y abono orgánico de alto valor nutricional (IUCN, 2008); siendo producidas en las praderas nativas durante el pastoreo y en los dormideros (Pinto et al., 2010), cuya acumulación permanente causa contaminación ambiental (Anexo 1), afecciones podales $\mathrm{y}$ predispone a enfermedades infecciosas y parasitarias (Molina et al., 2009). Se 
estima que una alpaca adulta produce en promedio 1.1 $\mathrm{t}$ de heces al año, siendo posible recuperar un 50\% de los campos (IUCN, 2008), y más lo producido en los dormideros se podría gestionar su implementación en biofermentos, los cuales promueven una mayor productividad y calidad de las cosechas mediante su aplicación foliar a las plantas, vía suelo o agua de riego (Trinidad \& Aguilar, 1999). El uso de biofermentos también restaura la fertilidad y la microbiota benéfica de los agro-ecosistemas dañados a causa del mal uso de agro-químicos, reduciendo la utilización y dependencia de estos (Adesemoye et al., 2008); y al provenir la materia prima de fuentes renovables, su producción y precios tienden a ser más estables (Rojas et al., 2015).

En la Agenda 21 como resultado de la Cumbre de la Tierra celebrada en Río de Janeiro en 1992, se recomendó el uso de biofertilizantes como alternativa para el desarrollo sostenible (Sequeiros, 1998); habiéndose desarrollado innovaciones biotecnológicas que hacen posible obtener bioabonos de mayor calidad que los biopreparados artesanales (bioles) en menor tiempo con el uso de microorganismos eficientes (EM) (Suárez, 2009). Los EM consisten en cultivos microbianos benéficos presentes en ecosistemas naturales (Higa \& Parr, 2013) que al entrar en contacto con la materia orgánica secretan sustancias benéficas e inhiben de manera controlada patógenos no deseados (Cóndor et al., 2007). Entre los principales tipos de EM se encuentran bacterias fotosintéticas, bacterias ácido lácticas (BAL), levaduras y actinomicetos, de amplia difusión y con múltiples aplicaciones biotecnológicas en más de 180 países (Higa \& Parr, 2013).

En el Laboratorio de Biotecnología Ambiental y Biorremediación del Departamento de Biología de la UNALM se han realizado diversas investigaciones basadas en la producción de abonos líquidos acelerados, los cuales resultan de la fermentación láctica de la materia orgánica con el consorcio microbiano B-Lac (Quiñones et al., 2016). El B-Lac está elaborado a base de BAL de los géneros Lactobacillus, Streptococcus y Bifidobacterium (García, 2008) (Tabla 1), los cuales producen ácidos orgánicos, bacteriocinas, preservantes, vitaminas, endulzantes, aromatizantes, sabores, antioxidantes, entre otros (Parra, 2010). Con ello ha sido posible obtener en 5 días bioabonos de alta calidad nutricional y microbiológica, con adecuados caracteres organolépticos y estables en el tiempo empleando estiércol de ganado, restos y organismos marinos, y residuos agro-industriales como principales insumos (Peralta et al., 2016). Según la cantidad y tipo de productos generados, la fermentación puede ser homoláctica cuando sólo se sintetiza ácido láctico, o heteroláctica cuando además se forma acetaldehído, etanol, glicerina y $\mathrm{CO}_{2}$ en proporciones equimolares (Axelsson, 2004). Para lograr una fermentación eficaz y consistente se recomienda el uso de melaza como fuente de carbono (Adesemoye et al., 2008);
Tabla 1: Análisis microbiológico del B-Lac.

\begin{tabular}{lc}
\hline \multicolumn{1}{c}{ Microorganismo } & Resultado \\
\hline Lactobacillus sp. $\left(\mathrm{UFC} \cdot \mathrm{ml}^{-1}\right.$ ) & $7 \times 10^{7}$ \\
Levaduras $\left(\mathrm{UFC} \cdot \mathrm{ml}^{-1}\right.$ ) & $2.5 \times 10^{5}$ \\
${\text { Mohos }\left(\mathrm{UFC} \cdot \mathrm{ml}^{-1} \text { ) }\right.}_{\text {Bacterias mesófitas viables }\left(\mathrm{UFC} \cdot \mathrm{ml}^{-1} \text { ) }\right.}$ & $<.3 \times 10^{4}$ \\
${\text { Coliformes totales }\left(\mathrm{NMP} \cdot \mathrm{ml}^{-1} \text { ) }\right.}^{\text {Coliformes fecales }\left(\mathrm{NMP} \cdot \mathrm{ml}^{-1} \text { ) }\right.}$ & $<3$ \\
\hline Nota: Valores $<3 \mathrm{y}<10$ indican ausencia de $^{2}$ & $<3$ \\
icroorganismos. & \\
*NMP; UFC: Número Más Probable; Unidades \\
Formadoras de Colonia. \\
Fuente: García (2008).
\end{tabular}

igualmente el lactosuero resulta apropiado por su aporte de microorganismos lácticos (Ramírez et al., 2011), y cuyo aprovechamiento contribuye a reducir los impactos ambientales generados por su alto desperdicio y elevada capacidad contaminante (Trujillo et al., 1998).

Ante un contexto actual de inseguridad alimentaria y cambio climático que afecta a las zonas altoandinas por su mayor pobreza y la fragilidad de sus ecosistemas (FAO, 2005), el uso de abonos líquidos permitiría incrementar la productividad y calidad de los pastos, forrajes y cultivos agrícolas que sustenta al ganado, a sus pobladores y a gran parte de la población nacional (Ticona et al., 2016). En el presente estudio se evaluó la calidad nutricional, carga bacteriana enteropatógena y la fitotoxicidad de un abono líquido acelerado elaborado con heces de alpaca, lactosuero bovino, melaza y el consorcio microbiano B-Lac; a fin de determinar su viabilidad de uso en campo. Al ser un trabajo pionero orientado a los agro-ecosistemas altoandinos, sus resultados establecen las bases para mejorar la gestión de los residuos pecuarios mediante innovación biotecnológica rápida, eficaz y sencilla, con beneficios económicos y ambientales.

\section{Materiales y métodos.}

I. Área de estudio y duración

El estudio se realizó en el Laboratorio de Biotecnología Ambiental y Biorremediación del Departamento de Biología de la UNALM, donde se elaboró un abono líquido acelerado con heces de alpaca provenientes de la SAIS Pachacútec S.A.C., situada en el distrito de Marcapomacocha, provincia de Yauli, Región Junín. Las canchas de pastoreo se sitúan entre el Nevado La Viuda y el Misipañahuin, entre 4400 a 5 200 msnm, a $11^{\circ} 20^{\prime} 45^{\prime \prime}$ ' de latitud Sur y $76^{\circ} 24^{\prime} 16.3^{\prime \prime}$ de longitud Oeste, sobre suelos de fisiografía variable del tipo litosol (Quiñones et al., 2016). La duración fue de 5 semanas, desde el 9 de setiembre al 13 de octubre del 2014.

II. Tratamientos y análisis de datos

Se prepararon 25 biofermentos por triplicado basados en la combinación de 5 niveles de B-Lac y 5 niveles de melaza $(0 \%, 5 \%, 10 \%, 15 \%$ y $20 \%$ de cada uno). Considerando mezclas de $0.5 \mathrm{Kg}$ por envase, se 
Tabla 2: $\mathrm{pH}$ del mejor tratamiento en diferentes escalas y temperaturas.

\begin{tabular}{ccccccc}
\hline \multirow{2}{*}{ Temperatura } & \multicolumn{7}{c}{$\mathrm{pH}$} \\
\cline { 2 - 7 } & Día 0 & Día 1 & Día 2 & Día 3 & Día 4 & Día 5 \\
\hline $0.5 \mathrm{Kg}\left(40^{\circ} \mathrm{C}\right)$ & 6.16 & 4.06 & 4.01 & 4.15 & 3.65 & 3.57 \\
$50 \mathrm{Kg}\left(40^{\circ} \mathrm{C}\right)$ & 5.94 & 4.07 & 3.60 & 3.58 & 3.53 & 3.42 \\
$50 \mathrm{Kg}\left(25^{\circ} \mathrm{C}\right)$ & 5.79 & 5.27 & 4.02 & 3.91 & 3.72 & 3.55 \\
\hline
\end{tabular}

calcularon las cantidades fijas de B-Lac y melaza para cada tratamiento, completando la diferencia con heces de alpaca y lactosuero bovino en igual proporción (Ver Anexo 2). Los envases rotulados fueron cubiertos con bolsas de plástico sujetadas con ligas de hule y luego tapados herméticamente, incubándose en una estufa a $40{ }^{\circ} \mathrm{C}$ por 5 días (tiempo óptimo de fermentación), midiendo diariamente el $\mathrm{pH}$ con potenciómetro, cuyo descenso garantiza la ausencia de patógenos no deseados (Carrasco et al, 2002). Las mediciones al quinto día se analizaron mediante la aplicación del software estadístico SAS versión 8.0, en un diseño completo al azar con arreglo factorial $5 x$ 5; realizando un Análisis de Varianza y la Prueba de Tukey $(\mathrm{p}<0.05)$. Para la elección del mejor tratamiento también se consideró el costo y accesibilidad de los insumos, monitoreando después el pH hasta el día 30 (Tabla 2).

III. Determinación de la calidad

A fin de generalizar el proceso a condiciones de campo se prepararon $100 \mathrm{Kg}$ del tratamiento elegido. La mitad de la mezcla inicial se fermentó por 5 días en un bidón de $60 \mathrm{~L}$ de capacidad, expuesto a la temperatura interna del laboratorio $\left(20-25{ }^{\circ} \mathrm{C}\right)$, y lo restante se incubó en una estufa a $40{ }^{\circ} \mathrm{C}$. Ambos envases fueron cubiertos con una bolsa de polietileno y tapados herméticamente. Mediante prensado mecánico se filtró el biofermento (cosecha), denominándose al efluente líquido “Alpa-biol”, al cual se le midió el pH, la conductividad eléctrica y la densidad, mediante potenciometría, conductimetría y el método de la probeta, respectivamente. El residuo sólido (biosol) no fue analizado ya que su uso resulta poco práctico (Soria et al., 2001).

III.1 Parámetros fisico-químicos

Se realizó una caracterización de macro-nutrientes (C, N, P, K, Ca, Mg, Na); micro-nutrientes (Fe, Cu, Zn, $\mathrm{Mn}, \mathrm{B})$, y metales pesados (Cd, $\mathrm{Pb}, \mathrm{Cr}$ ) en el Laboratorio de Suelos, Plantas, Aguas y Fertilizantes (LASPAF-UNALM). Para la determinación del contenido de $\mathrm{C}, \mathrm{N}, \mathrm{P}$ y $\mathrm{B}$ se emplearon los métodos estandarizados de Walkley y Black, Kjeldahl, Amarillo de Vanadato y Curmina, respectivamente; mientras que la determinación del contenido de $\mathrm{K}, \mathrm{Ca}, \mathrm{Mg}, \mathrm{Na}, \mathrm{Fe}$, $\mathrm{Cu}, \mathrm{Zn}, \mathrm{Mn}, \mathrm{Cr}, \mathrm{Pb}$ y $\mathrm{Cd}$ se realizó mediante espectrometría de absorción atómica.
La relación Carbono-Nitrógeno (C: N) se calculó mediante el cociente entre ambos parámetros a partir de los resultados de caracterización nutricional; siendo un parámetro que permite un mejor manejo agrícola en cuanto a la estabilidad del biofermento (Peralta et al., 2016), ya que está relacionado con la provisión adecuada de sustrato a los microorganismos (Soria et al., 2001).

El contenido nutricional fue comparado con los parámetros del Biolac ${ }^{\circledR}$ (Tabla 3), un abono foliar elaborado con EM de amplio uso en el sector agropecuario, producido por NOGAFER-PERÚ S.A.C. (Ayala, 2015). Al no existir normativas que regulen las concentraciones de metales pesados en abonos líquidos se realizó la comparación con los parámetros para compost establecidos por la Unión Europea (Brinton, 2000). También mediante una prueba de alcohol (etanol) se determinó el tipo de fermentación (homoláctica o heteroláctica) en el Laboratorio de Servicios de Análisis Químico (LASAQ-UNALM), mediante la técnica descrita por la AOAC (2012).

III.2 Población microbiana

Se determinó la población de coliformes totales, coliformes fecales y E. coli, en el Laboratorio de Ecología Microbiana y Biotecnología "Marino Tabusso" de la UNALM con el método del Número más Probable (NMP) establecido por la ICMSF (1983); comparándose con los parámetros del Decreto Supremo $\mathrm{N}^{\circ}$ 002-2008-MINAM, concerniente a Estándares Nacionales de Calidad para Agua de Riego de vegetales (Diario Oficial El Peruano, 2008). También se determinó la población de Lactobacillus (Tabla 4), mediante la técnica de conteo en placa de Unidades Formadoras de Colonias (UFC) propuesta por la ICMSF (1983).

\section{III.3 Fitotoxicidad}

Se determinó los efectos fitotóxicos del Alpa-biol en un ensayo de toxicidad aguda, recomendado para evaluar los riesgos ambientales causados por sustancias desconocidas (Zucconi et al., 1981). Para ello se utilizó semillas de lechuga variedad Duett, por su rápida germinación y alta sensibilidad a sustancias fitotóxicas, cuyos resultados son genéricos para la mayoría de semillas o plántulas (Sobrero \& Ronco, 2004). En

Tabla 3: Comparación nutricional entre el Alpa-biol y el Biolac ${ }^{\circledR}$.

\begin{tabular}{lcccccccccccc}
\hline \multirow{2}{*}{ Bioabonos } & \multicolumn{4}{c}{ Macronutrientes $\left(\mathrm{g} \cdot \mathrm{L}^{-1}\right)$} & \multicolumn{4}{c}{ Micronutrientes $\left(\mathrm{mg} \cdot \mathrm{L}^{-1}\right)$} \\
\cline { 2 - 14 } & $\mathrm{C}$ & $\mathrm{N}$ & $\mathrm{P}$ & $\mathrm{K}$ & $\mathrm{Ca}$ & $\mathrm{Mg}$ & $\mathrm{Na}$ & $\mathrm{Fe}$ & $\mathrm{Cu}$ & $\mathrm{Zn}$ & $\mathrm{Mn}$ & $\mathrm{B}$ \\
\hline Alpa-biol & 79.48 & 3.70 & 0.66 & 8.70 & 3.33 & 12.50 & 0.59 & 280.45 & 2.40 & 11.65 & 71.80 & 7.80 \\
Biolac $^{\circledR}$ & 28.89 & 1.63 & 0.07 & 4.24 & 0.12 & 0.40 & 0.15 & 13.34 & 0.40 & 0.63 & 0.18 & 6.00 \\
\hline
\end{tabular}




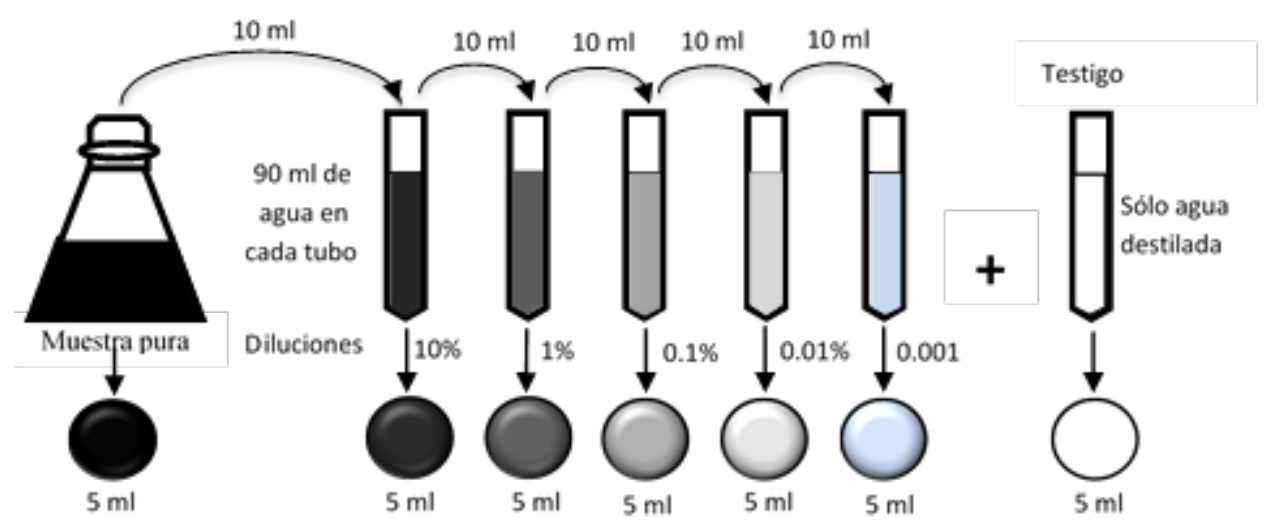

Figura 1. Diluciones del Alpa-biol.

discos de papel filtro colocados sobre placas de Petri esterilizadas se embebió $5 \mathrm{ml}$ de Alpa-biol puro y diluido al $10 \%, 1 \%, 0.1 \%, 0.01 \%, 0.001 \%$, y un testigo de sólo agua destilada (Figura 1), a razón de 3 placas por dosis. Se distribuyeron 20 semillas en cada cápsula y estas se almacenaron en una caja de tecnopor a $25^{\circ} \mathrm{C}$ por 120 horas. Se calculó el porcentaje de geminación relativo (PGR), el porcentaje de crecimiento de radícula relativo (CRR) (Figura 2), y con estos los Índices de Germinación (IG) para cada dosis, mediante las siguientes ecuaciones (Tiquia, 2000):

$\boldsymbol{P G R}(\%)=\frac{N^{\circ} \text { de semillas germinadas en el extracto }}{N^{\circ} \text { de semillas germinadas en el testigo }} \times 100$

$\boldsymbol{C} \boldsymbol{R} \boldsymbol{R}(\%)=\frac{\text { Elongación de radícula en el extracto }}{\text { Elongación de radícula en el testigo }} \times 100$

$$
\boldsymbol{I G}(\%)=\frac{P G R \times C R R}{100}
$$

Según Zucconi et al. (1981), las dosis que confieren un IG entre 80 a $100 \%$ indican ausencia de sustancias fitotóxicas; mientras que valores entre 50 a $80 \%$ e inferiores a $50 \%$, presentan moderada y alta cantidad de estas sustancias, respectivamente.

\section{Resultados y discusión.}

I. Elección y evaluación del mejor tratamiento

Hubo un descenso drástico del pH en todos los tratamientos al primer día de fermentación y luego un decremento paulatino hasta el quinto día (Ver Anexo 2). Según Garcés et al. (2004), esto se debe a la elevada concentración de ácidos orgánicos sintetizados por las BAL a partir de la materia orgánica en condiciones de anaerobiosis y presencia de sustrato energético. Diversas investigaciones realizadas en el Laboratorio de Biotecnología Ambiental y Biorremediación de la UNALM reportan resultados similares mediante el tratamiento anaerobio de estiércoles, organismos y restos marinos, y sub-productos agro-industriales con el consorcio microbiano B-Lac (Peralta et al., 2016), considerando al $\mathrm{pH}$ como principal indicador de la eficiencia fermentativa durante el monitoreo.

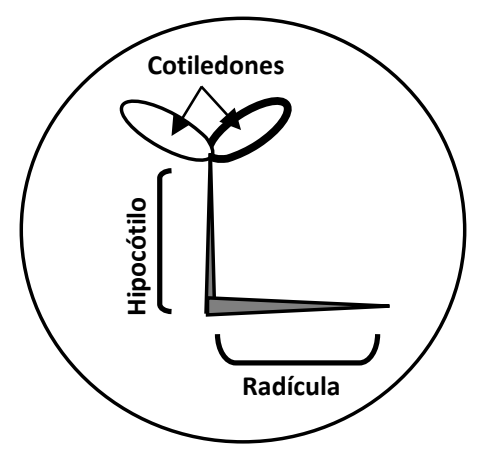

Figura 2. Morfología de Lactuca Sativa L. en crecimiento (Sobrero \& Ronco, 2004).

Con el ANOVA de 2 criterios se determinó que la acidez de los tratamientos se incrementó en forma significativa debido al efecto de la melaza $(\mathrm{p}<0.0001)$, del B-Lac $(\mathrm{p}<0.0001)$ y por el efecto de interacción entre ambos $(p=0.0025)$ (Figura 3$)$. Los tratamientos carentes de melaza y B-Lac presentaron un $\mathrm{pH}$ altamente ácido menor a 4.0; sin embargo diferían significativamente (según la Prueba de Tukey) con el promedio de $\mathrm{pH}$ de los niveles superiores (5\%, 10\%, $15 \%$ y $20 \%$ ), los cuales presentaron similitud estadística (Ver Anexo 2).
Tabla 4: Carga bacteriana de las heces de alpaca y del Alpa-biol.

\begin{tabular}{lcc}
\hline \multicolumn{1}{c}{ Microorganismo } & Heces de alpaca & Alpa-biol \\
\hline Coliformes totales (NMP·g ${ }^{-1}$ ) & $>11 x 10^{4}$ & $<3^{*}$ \\
Coliformes fecales $\left(\mathrm{NMP} \cdot \mathrm{g}^{-1}\right.$ ) & $>11 \chi 10^{4}$ & $<3^{*}$ \\
E. Coli $\left(\mathrm{NMP} \cdot \mathrm{g}^{-1}\right.$ ) & $<3^{*}$ & $<3^{*}$ \\
Lactobacillus $\left(\mathrm{UFC} \cdot \mathrm{g}^{-1}\right)$ & $29 x 10^{4}$ & $53 \chi 10$ \\
\hline
\end{tabular}

*Los valores $<3 \mathrm{y}<10$ indican ausencia de microorganismos. 


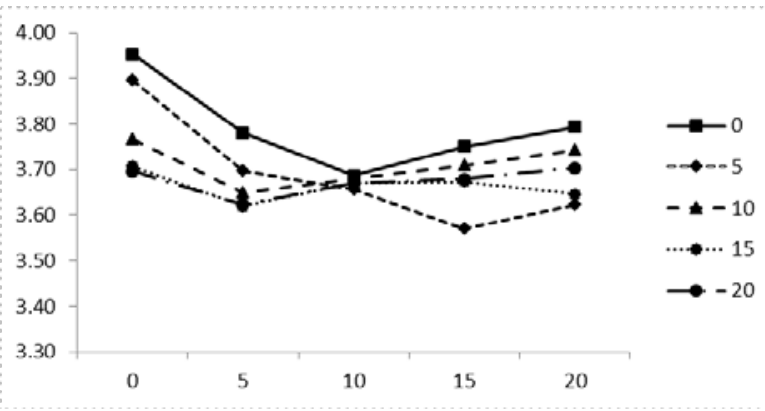

Figura 3. Interacción entre el B-Lac y la melaza al quinto día de fermentación.

Además, los tratamientos carentes de B-Lac presentaron olor fétido por la ausencia de BAL, microorganismos predominantes en el B-Lac (Tabla 1), por lo cual fueron descartados al igual que los carentes de melaza.

El tratamiento de elección fue el T9, compuesto por $5 \%$ de B-Lac, $15 \%$ de melaza, $40 \%$ de heces de alpaca y $40 \%$ de lactosuero, por su mayor acidez $(\mathrm{pH}=3.57)$ y menor contenido de B-Lac (el insumo más caro y menos accesible). El T9 tenía sabor agridulce, no presentó olor fétido, y mantuvo su pH casi constante por 30 días (Figura 4). Según Vásquez et al. (2009), las BAL inhiben patógenos no deseados, permitiendo alargar la vida útil de los bioproductos. García (2008) señala que la estabilidad en biofermentos acelerados está dada en función de su acidez por periodos mayores a 6 meses; coincidiendo con los resultados de Ortega \& Arias (2015), basados en la evaluación de la estabilidad de un bioproducto compuesto por microorganismos benéficos conservado a temperatura ambiente por 6 meses, con mínima variación de la acidez y carga microbiana. En base a esto se considera que el Alpabiol es un bioabono estable en el tiempo.

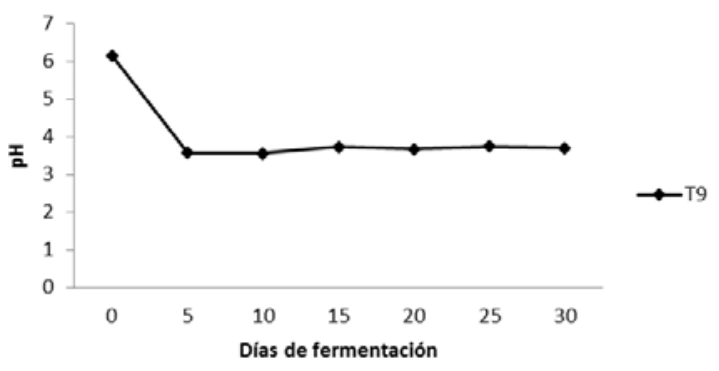

Figura 4. Variación del pH del mejor tratamiento durante 30 días.

La variación del pH del T9 fue similar en diferentes escalas $(0.5 \mathrm{Kg} \& 50 \mathrm{Kg})$ y condiciones de temperatura $\left(40{ }^{\circ} \mathrm{C} \& 20-25^{\circ} \mathrm{C}\right.$ ) (Tabla 2), ya que el B-Lac contiene cepas de BAL mesófilas viables (García, 2008) con temperatura óptima entre $20-25^{\circ} \mathrm{C}$ (Parra, 2010). Por tanto, los resultados favorecen la generalización de la presente biotecnología en condiciones de campo donde la energía térmica es un factor limitante.

II. Determinación de la calidad del bioabono líquido (Alpa-biol)

Se obtuvo un 57\% de extracto líquido (Alpa-biol) altamente ácido $(\mathrm{pH}=3.83)$ de consistencia viscosa, producido mediante fermentación homoláctica según el reporte de laboratorio que indicó ausencia de etanol (Grado alcohólico a $20 / 20^{\circ} \mathrm{C}=0 \%$ ), considerando que la mayoría de Lactobacilllus son homofermentadores, con un rango de tolerancia de $\mathrm{pH}$ que fluctúa entre 1.1 a 5.5 (Corrales et al., 2015). Esta condición resulta incompatible para la mayoría de bacterias enteropatógenas, putrefactivas, metanogénicas, mohos y levaduras (Adesemoye et al., 2008), razón por la cual no se generaron gases durante la fermentación, hecho que fue verificado al no observarse inflación en las bolsas que cubrían a los recipientes durante el periodo fermentativo. En tal sentido la producción de Alpa-biol tiene mayor viabilidad que los biopreparados artesanales (bioles), que normalmente se cosechan entre los 60 a 90 días dependiendo de las condiciones medio-ambientales (Peralta et al., 2016) y generan altas emisiones de metano por la predominancia de enteropatógenos (Soria et al., 2001).

II.1 Caracteres organolépticos

Alejo et al. (2015) sostienen que el uso de microorganismos lácticos contribuye al desarrollo de las propiedades organolépticas en el sustrato sobre el que actúan; y en efecto el Alpa-biol presentó un aroma sutil de azúcar fermentada, ya que las BAL convierten la lactosa en alcoholes de azúcar (polioles) como manitol, sorbitol, diacetilo y acetaldehído (Parra, 2010). El color fue marrón oscuro, indicando una mayor capacidad para absorber la luz solar, resultando en una mayor eficiencia fotosintética y retención de calor (Rojas et al., 2015). Asimismo se percibió un sabor agridulce conferido por los ácidos orgánicos, edulcorantes, acetaldehído, diacetilo (por fermentación de citratos) y péptidos sintetizados por las BAL mediante lipólisis y proteólisis (Parra, 2010).

II.2 Evaluación de parámetros fisico-químicos

II.2.1 Caracteres fisico-químicos

El Alpa-biol presentó una elevada acidez ( $\mathrm{pH}=$ 3.83), lo cual según Fernández et al. (2013) \& Peralta et al. (2016) favorece la fijación de nutrientes al hacerlos más solubles y por tanto más disponibles para su absorción por las plantas. Asimismo cuando la acidez aumenta se solubilizan los gases de efecto invernadero como metano y dióxido de carbono, reduciéndose la contaminación ambiental (Félix et al, 2008). Igualmente la salinidad resultó muy elevada (23.4 dS. $\left.\mathrm{m}^{-1}\right)$; condición que indica altas concentraciones de iones solubles (Soria et al., 2001); debido a la intensa actividad de las BAL para degradar la materia orgánica y por la elevada concentración de potasio aportada por la melaza (3.6\%) (De Blas et al., 2010). Al respecto Soria et al. (2001) señalan que el 
principal problema de la aplicación de bioproductos puros son sus efectos de toxicidad por sales, siendo común la quema del follaje.

Ayers \& Westcott (1985) de la FAO consideran que una salinidad mayor a $3.0 \mathrm{dS} \cdot \mathrm{m}^{-1}$ en aguas de riego son perjudiciales en la mayoría de cultivos; mientras que valores entre 0.7 a $3.0 \mathrm{dS} \cdot \mathrm{m}^{-1}$ representan un riesgo entre ligero a moderado. Por ello se sugiere la dilución de los biofermentos en agua a fin de neutralizar sus efectos nocivos (Soria et al., 2001), permitiendo además reducir los costos de producción por unidad de producto obtenido, lo cual implica indirectamente mayores beneficios económicos para fines de comercialización, según el grado de dilución óptimo (Quiñones et al., 2016).

\section{II.2.2 Contenido de nutrientes}

El Alpa-biol posee mayores concentraciones de macro y micro-nutrientes con respecto al Biolac ${ }^{\circledR}$ (Tabla 3), y a los parámetros recomendados por Suárez (2009) para bioles de producción artesanal, quien propone concentraciones de $\mathrm{N}, \mathrm{P}, \mathrm{K}$, Ca y B mayores a $700 \mathrm{mg} \cdot \mathrm{L}^{-1}, 170 \mathrm{mg} \cdot \mathrm{L}^{-1}, 1300 \mathrm{mg} \cdot \mathrm{L}^{-1}, 1800 \mathrm{mg} \cdot \mathrm{L}^{-1}$, $270 \mathrm{mg} \cdot \mathrm{L}^{-1}$ y $7 \mathrm{mg} \cdot \mathrm{L}^{-1}$, respectivamente. Esta notable diferencia se atribuye a la alta capacidad de las BAL para degradar compuestos insolubles como la celulosa, hemicelulosa y lignina (Cóndor et al., 2007); explicándose con ello los altos contenidos de materia orgánica $\left(137.02 \mathrm{~g} \cdot \mathrm{L}^{-1}\right)$, sólidos totales $\left(177.88 \mathrm{~g} \cdot \mathrm{L}^{-1}\right)$ y densidad $\left(1.057 \mathrm{~g} \cdot \mathrm{ml}^{-1}\right)$. La relación C: $\mathrm{N}$ está dentro del rango óptimo para biofermentos (Tabla 3) que va de 20:1 a 30:1, con lo cual los microorganismos logran un óptimo crecimiento y una buena digestión de la materia orgánica; considerando que altas concentraciones de nitrógeno amoniacal implican pérdidas por volatilización y además resulta tóxico; mientras que su deficiencia afecta el crecimiento de los agregados bacterianos (Soria et al., 2001).

II.2.3 Metales pesados

El Alpa-biol presentó $0.03 \mathrm{mg} \cdot \mathrm{L}^{-1}, 0.28 \mathrm{mg} \cdot \mathrm{L}^{-1} \mathrm{y}$ $0.02 \mathrm{mg} \cdot \mathrm{L}^{-1}$ de cadmio, cromo y plomo, respectivamente; muy inferiores a los parámetros para compost establecidos por la Unión Europea, los cuales oscilan entre $0.7-1.0 \mathrm{mg} \cdot \mathrm{Kg}^{-1}$, 70- $200 \mathrm{mg} \cdot \mathrm{Kg}^{-1}$ y 70 $1000 \mathrm{mg} \cdot \mathrm{Kg}^{-1}$ para cadmio, cromo y plomo, respectivamente (Brinton, 2000). Por tanto, el Alpabiol es un abono de Clase A (sin restricciones de uso), según la clasificación del compost establecida por la Norma chilena (Nch 2880, 2004).

\section{II.3 Población microbiana}

Las poblaciones de coliformes fecales, totales y $E$. coli fueron inferiores a los límites de detección por la técnica de Número más Probable ( $<3 \mathrm{NMP} \cdot \mathrm{g}^{-1}$ ), lo cual se interpreta como ausencia en el ensayo, evidenciando una reducción total de la carga enteropatógena a partir de las heces frescas de alpaca (Tabla 4). Peralta et al. (2016) obtuvieron resultados similares con heces de ganado vacuno tratadas con B-Lac, y según Parra (2010), esto se debió al efecto supresor de las BAL sobre cepas competidoras, principalmente mediante la producción de ácidos orgánicos y bacteriocinas. Un pH ácido desestabiliza los componentes celulares y funcionales como las proteínas, condición que no afecta a las BAL ya que estas poseen un mecanismo de expulsión de hidrogeniones al exterior celular (Madigan et al., 2004); mientras que las bacteriocinas consisten en péptidos que se anclan a la membrana celular formando poros (Figura 5), lo cual provoca pérdida del potencial de membrana (Cotter et al., 2005). El espectro de acción de las BAL comprende enteropatógenos como: $E$. coli, Salmonella, Streptococcus, Staphylococcus aureus, Campilobacter, Clostridium botulinum, Listeria monocitogenes, entre otros (Carrasco et al., 2002).

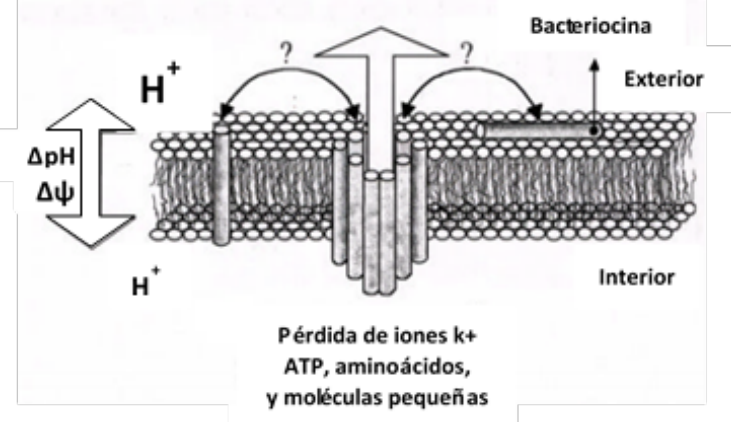

Figura 5. Mecanismo de acción general de las bacteriocinas (Cotter et al., 2005).

La presencia de Lactobacillus en el Alpa-biol (53 $x 10$ $\mathrm{UFC} \cdot \mathrm{g}^{-1}$ ) se considera benéfica (Tabla 4 ), por la acción fitosanitaria que estos ejercen cuando se aplican sobre las semillas, superficies de plantas o el suelo; ya que actúan sinérgicamente con la microbiota benéfica para promover una mejor asimilación de nutrientes. Los Lactobacillus también suprimen la propagación de fitopatógenos perjudiciales como el Fusarium sp. y nematodos mediante la producción de sustancias bioactivas como el ácido láctico (Cóndor et al., 2007); en consecuencia, las plantas ejercen un efecto repelente sobre muchos tipos de insectos y plagas aumentando la fertilidad, acortando los ciclos productivos y restableciendo el equilibrio microbiológico de los ecosistemas (Adesemoye et al., 2008).

\section{II.4 Fitotoxicidad}

Los efectos letales sobre la germinación de la lechuga (Lactuca sativa L.) se observaron con la inoculación del Alpa-biol puro y diluido al 10\% (Figura 6), indicando una fuerte presencia de sustancias fitotóxicas, según Zucconi et al. (1981). Al respecto, Zapata et al. (2005) afirman que estos casos se deben a una alta concentración de sales; considerando que la tolerancia de la lechuga a la salinidad oscila entre 1.4 a $2.0 \mathrm{dS} \cdot \mathrm{m}^{-1}$ (Faquin \& Furlani, 1999), parámetro que es considerado para el monitoreo de este cultivo en hidroponía. Otro factor implicado es la acidez, ya que el pH óptimo de la lechuga es de 5.8 (Andriolo et al., 
Tabla 5: Parámetros asociados al ensayo de toxicidad aguda.

\begin{tabular}{lccccccc}
\hline \multicolumn{1}{c}{ Dosis } & $\mathrm{pH}$ & $\mathrm{CE}\left(\mathrm{dS} \cdot \mathrm{m}^{-1}\right)$ & $\mathrm{N}^{\circ}$ Semillas germinadas & PGR $(\%)$ & Elongación radicular $(\mathrm{cm})$ & $\mathrm{CRR}(\%)$ & IG $(\%)$ \\
\hline Control & 7.94 & 0.52 & 15.67 & 100.00 & 13.00 & 100.00 & 100.00 \\
$0.001 \%$ & 7.79 & 0.65 & 9.33 & 59.54 & 12.67 & 97.44 & 58.01 \\
$0.01 \%$ & 7.62 & 0.88 & 11.67 & 74.47 & 12.33 & 94.87 & 70.65 \\
$0.1 \%$ & 7.48 & 0.82 & 16.00 & 102.11 & 12.00 & 92.31 & 94.25 \\
$1 \%$ & 5.87 & 1.06 & 5.33 & 34.01 & 7.13 & 54.87 & 18.66 \\
$10 \%$ & 4.15 & 3.96 & - & - & - & - & - \\
$100 \%$ & 3.95 & 23.40 & - & - & - & - & - \\
\hline
\end{tabular}

2005), comparado con los valores extremadamente ácidos que la dosis pura $(\mathrm{pH}=3.95)$ y su dilución al $10 \%(\mathrm{pH}=4.15)$ proporcionan (Tabla 5). Por ello el Alpa-biol tuvo que diluirse al $0.1 \%$ para neutralizar los efectos fitotóxicos de su elevada acidez y salinidad, confiriendo el mayor IG (94.26\%); mientras que las dosis más diluidas $(0.01 \%$ y $0.001 \%)$ resultaron ser insuficientes para lograr un mejor efecto (Tabla 5 y Figura 6). Con la dilución al $0.1 \%$ la salinidad se redujo a $0.82 \mathrm{dS} \cdot \mathrm{m}^{-1}$, valor que no indica problema para su uso en campo, según la clasificación de aguas de riego establecida por la FAO (Ayers \& Westcott, 1985) y los Estándares Nacionales de calidad del agua de riego (Diario Oficial El Peruano, 2008).

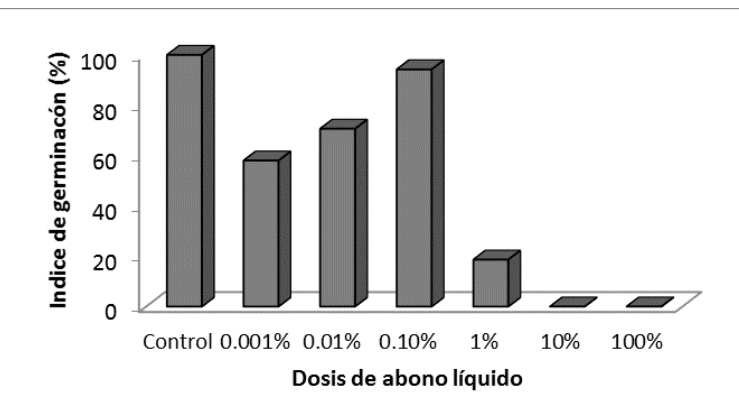

Figura 6. Índices de germinación de

Lactuca sativa $L$.

\section{Conclusiones.}

1. La fermentación de heces de alpaca, lactosuero bovino, melaza y B-Lac en proporción 40: 40: 15: 5, respectivamente, genera en 5 días un abono líquido inocuo, de alta calidad nutricional, con adecuados caracteres organolépticos y estable en el tiempo (Alpabiol); siendo necesario diluirlo al $0.1 \%$ para neutralizar los efectos fitotóxicos de su elevada acidez y salinidad, para su uso en campo.

2. La variación de $\mathrm{pH}$ del Alpa-biol es similar en diferentes escalas $(0.5 \mathrm{Kg}$ y $50 \mathrm{Kg})$ y condiciones de temperatura (20- $25{ }^{\circ} \mathrm{C}$ y $40{ }^{\circ} \mathrm{C}$ ); lo cual favorece la generalización de la presente biotecnología en condiciones de campo, donde la energía térmica es un factor limitante.

\section{Agradecimientos.}

Al Consejo Nacional de Ciencia, Tecnología e Innovación tecnológica (CONCYTEC), por su apoyo económico para la realización del presente trabajo mediante el Contrato Nº 018- 2013-II/ FONDECYT y a la SAIS Pachacútec S.A.C. por su gentil acogida y facilidades brindadas durante la fase de campo.

\section{Literatura citada.}

Adesemoye A.O., Torbert H.A. \& Kloepper J.W. 2008. Enhanced plant nutrient use efficiency with PGPR and AMF in an integrated nutrient management system. Canadian Journal of Microbiology. 54 (10): 876-886.

Andriolo J.L., Luz G.L., Witter M.H., Godoi R.S., Barros G.T. \& Bortolotto O.C. 2005. Growth and yield of lettuce plants under salinity. Horticultura Brasileira. 23 (4): 931934.

AOAC (Association of Official Analytical Chemists). 2012. $19^{\text {th }}$ Edition. Official Method 2008.01. AOAC International. Gaithersburg, Maryland, USA.

Ayala D. 2015. Vigor de shihuahuaco (Dypteryx spp.) y biomasa microbiana de suelos degradados en selva con dos biofertilizantes. Tesis de Maestría en Suelos. Universidad Nacional Agraria La Molina, Lima, Perú. 64 p.

Axelsson L. 2004. Acid lactic bacteria: Classification and physiology. In: Salminem S., Wright A.V., Ouwehand A.C. (eds.). Lactic Acid Bacteria: Microbiological and Functional Aspects. $3^{\text {ed }}$ edition. Marcel Dekker Inc., New York, USA. pp. 1-66.

Ayers R.S. \& Westcott D.W. 1985. Water quality for agriculture. FAO. Irrigation and Drainage Paper 29. Rev. 1, Rome, Italy. $174 \mathrm{p}$.

Brinton W.F. 2000. Compost Quality Standards \& Guidelines. Final Report by Woods End Research Laboratory for the New York State Association of Recyclers. New York, USA. 42 p.

Carrasco M.S., Scarincini H.E. \& Simonetta A.C. 2002. Antibacterial Activity of Lactic Acid Bacteria Isolated from Argentinian Dairy Products. The Australian Journal of Dairy Technology. 57 (1): 15-19.

Cóndor A.F., Gonzáles P. \& Lokare C. 2007. Effective Microorganisms: Myth or reality? Revista Peruana de Biología. 14 (2): 315-319.

Corrales L.C., Antonilez D.M., Bohórquez J.A. \& Corredor A.M. 2015. Anaerobic bacteria: Processes they perform and their contribution to life sustainability on the planet. NOVA. 13 (23): 55-81.

Cotter P. D., Hill C. \& Ross R.P. 2005. Bacteriocins: Developing innate immunity for food. Nature Reviews of Microbiology. 3 (10): 777-788.

De Blas C., Mateos G.G. \& García P. 2010. Tablas FEDNA de composición y valor nutritivo de alimentos para la fabricación de piensos compuestos. $3^{\mathrm{a}}$ ed. Madrid, España. 502 p.

Diario Oficial El Peruano. 2008. Decreto Supremo $N^{\circ} 002-$ 2008-MINAM. Estándares Nacionales de Calidad 
Ambiental para Agua (ECA). Categoría 3: Riego de vegetales de tallo bajo y tallo alto (Anexo D).

FAO (Organización de las Naciones Unidas para la Agricultura y la Alimentación). 2005. Situación actual de los Camélidos Sudamericanos en Perú. Proyecto de cooperación técnica en apoyo a la crianza y aprovechamiento de los Camélidos Sudamericanos en la Región Andina (TCP/RLA/2914). Santiago de Chile. 63 p.

Faquin V. \& Furlani P.R. 1999. Cultivo de hortaliças de folhas em hidroponia em ambiente protegido. Informe Agropecuário (Brasil). 20 (200/201): 99-104.

Félix J.A., Sañudo R.R., Rojo G.E, Martínez R. \& Olalde V. 2008. Importancia de los abonos orgánicos. Ra Ximhai. 4 (1): 57-67.

Fernández S. 1991. Avances y perspectivas del conocimiento de los camélidos sudamericanos. FAO. Santiago de Chile. pp. 327-335.

Fernández V., Sotiropoulos T. \& Brown P. 2013. Foliar Fertilization Scientific Principles and Field Practices. $1^{\text {th }}$ ed. International Fertilizer Industry Association (IFA), Paris, France. 140 p.

Garcés A., Berrio L., Ruiz S., Serna G. \& Builes A. 2004. Ensilaje como fuente de alimentación para el ganado. Revista Lasallista de Investigación. 1 (1): 66-71.

García L.A. 2008. Uso de bacterias probióticas en el ensilado de residuos de pescado. Tesis para optar el título de Biólogo. Universidad Nacional Agraria La Molina, Lima, Perú. 142 p.

Higa T. \& Parr J.F. 2013. Microorganismos benéficos y efectivos para una agricultura y medio ambiente sostenibles. Beltsville, Maryland, Estados Unidos: Centro Internacional de Investigación de Agricultura Natural y Departamento de Agricultura de los Estados Unidos. 13 p.

ICMSF (International Commission on Microbiological Specifications for Foods). 1983. $2^{\text {nd }}$ ed. Vol. 1 Part 2, (Trad. 1988). Reimp. 2000. Editorial Acribia.

IUCN (Unión Internacional para la Conservación de la Naturaleza). 2008. Una perspectiva mundial sobre el valor económico total del pastoralismo. Informe de síntesis global basado en seis estudios del país. Instituto Internacional de Investigación Pecuaria (ILRI), Nairobi, Kenia. 27 p.

Madigan M.T, Martinko J.M. \& Parker J. 2004. Brock Biología de los Microorganismos. Décima edición. Pearson Education, S.A. Madrid. pp. 398-401.

Molina D., López T., González A., Gómez L. \& Peso D. 2009. Cryptosporidium parvum como factor de riesgo en la diarrea neonatal en alpacas de Puno. Revista de Investigaciones Veterinarias del Perú. 20 (2): 263-269.

NCh 2880 (Norma Chilena de Compost). 2004. Norma Chilena Oficial. Compost-Clasificación y requisitos. Instituto Nacional de Normalización (INN). 19 p.

Ortega G.M. \& Arias M.E., 2015. Estudio de estabilidad del bioproducto Lebame. Instituto Cubano de Investigaciones de los Derivados de la Caña de Azúcar. 49 (3): 3-8.

Parra R.A. 2010. Bacterias ácido lácticas: Papel funcional en los alimentos. Revista de la Facultad de Ciencias Agropecuarias de la Universidad Pedagógica y Tecnológica de Colombia. 8 (1): 93-100.

Peralta L., Juscamaita J.G. \& Meza V. Obtención y caracterización de abono orgánico líquido a través del tratamiento de excretas del ganado vacuno de un establo lechero usando un consorcio microbiano ácido láctico. Ecología Aplicada. 15 (1): 1-10.

Pindi P.K. 2012. Liquid Microbial Consortium. A Potential Tool for Sustainable Soil Health. Journal of Fertilizers \& Biopesticides. 3 (4): 1-9.

Pinto C.E., Martín C. \& Vázquez M.D. 2010. Camélidos sudamericanos: Clasificación, origen y características. Revista Complutense de Ciencias Veterinarias. 4 (1): 2336.

Quiñones H.R., Trejo W.E. \& Juscamaita J.G. 2016. Producción de abono líquido acelerado con heces de alpaca, lactosuero bovino y melaza de caña mediante fermentación homoláctica. Tesis para optar el grado de Magister Scientiae. Universidad Nacional Agraria La Molina, Lima, Perú. 124 p.

Ramírez J.C., Rosas P., Velázquez M.Y., Ulloa J.A. \& Arce F. 2011. Bacterias lácticas: Importancia en alimentos y sus efectos en la salud. Revista Fuente (Nayarit). 2 (7): 116.

Rojas M.D., Sánchez J.D. \& Londoño L.M. 2015. Una estrategia de innovación en fertilizantes orgánicos mediante lógica difusa. Revista de la Facultad Nacional de Agronomía de Medellín, Colombia. 68 (1): 74237439.

Sequeiros L. 1998. De la III Cumbre de la Tierra (Río de Janeiro, 1992) al fracaso de la Conferencia de Kioto (1997): Claves para comprender mejor los problemas ambientales del Planeta. Enseñanzas de las Ciencias de la Tierra. 6 (1): 3-12.

Sobrero M.C. \& Ronco A. 2004. Ensayo de toxicidad aguda con semillas de lechuga (Lactuca sativa L.). pp. 71-79. En: G. Castillo (ed.) Ensayos Toxicológicos y Métodos de Evaluación de Calidad de Aguas. Ottawa-Canadá.

Soria M., Ferrera R., Etchevers J., Alcántara G., Trinidad J., Borges L. \& Pereyda G. 2001. Producción de biofertilizantes mediante biodigestión de excreta líquida de cerdo. Terra Latinoamericana. 19 (4): 353-362.

Suárez D.M. 2009. Caracterización de un compuesto orgánico producido en forma artesanal por pequeños agricultores en el Dpto. de Magdalena. Tesis de Maestría en Ciencias Agrarias con Énfasis en Suelos. Santa Marta, Colombia. 93 p.

Ticona O., Céspedes R., Martínez Z. \& Chipana G. 2016. Aplicación de Biol y riego por aspersión en la producción de cebada forrajera (Hordeum vulgare) en el municipio de Viacha. Revista de Investigación e Innovación Agropecuaria y de Recursos Naturales. 3 (3): 39-47.

Tiquia S.M. 2000. Evaluating phytotoxicity of pig manure from the pig on litter system. In: Warman P.R. \& Taylor B.R. (eds.). Proceedings of the International Composting Symposium. Nova Scotia, Canada. CBA Press. pp. 625647.

Trinidad A. \& Aguilar D. 1999. Fertilización foliar, un respaldo importante en el rendimiento de los cultivos. Terra Latinoamericana (México). 17 (3): 247-255.

Trujillo M., Suárez F. \& Gallego D. 1998. Fermentación láctica en contínuo a partir de suero dulce de leche desproteinizado. Revista Colombiana de Biotecnología. 1 (1): 45-50.

UNIDO (Organización de las Naciones Unidas para el Desarrollo Industrial). 2006. Producción textil de fibras de camélidos sudamericanos en el área altoandina de 
Bolivia, Ecuador y Perú. Sub-división de Promoción de Inversión y Tecnología. 52 p.

Vásquez S.M., Suárez H. \& Zapata S. 2009. Utilización de sustancias antimicrobianas producidas por bacterias ácido lácticas en la conservación de la carne. Revista chilena de Nutrición. 36 (1): 64-71.
Zapata N., Guerrero F. \& Polo A. 2005. Evaluación de corteza de pino y residuos urbanos como componentes de sustrato de cultivo. Agricultura Técnica (Chile). 65 (4): 378-387. Zucconi F., Peram A., Forte M. \& De Bertolidi M. 1981. Evaluating toxicity of inmature compost. Byocycle 22 (4): 54-57.

ANEXO 1: Registro fotográfico.

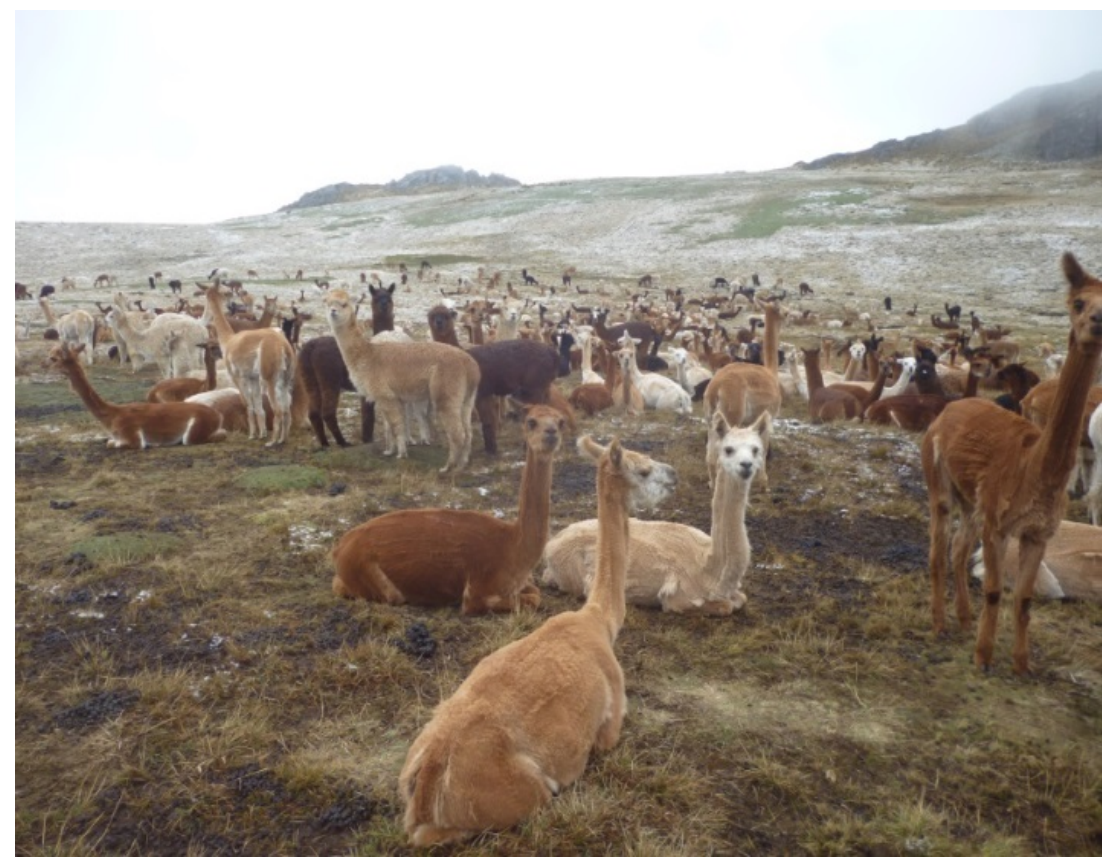

Fotografía 1. Alpacas en áreas de reposo (dormideros) a 5200 msnm.
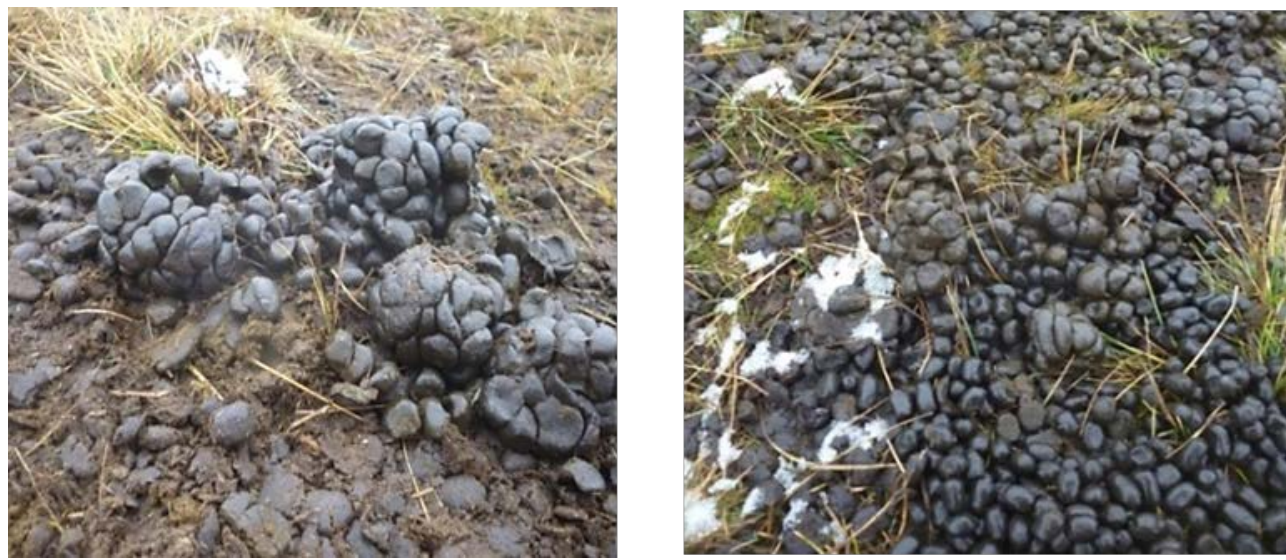

Fotografías 2 y 3. Producción de heces de alpaca y contaminación ambiental. 
ANEXO 2. Análisis de datos.

Tabla 6: $\mathrm{pH}$ de los tratamientos y Prueba de Tukey $(\mathrm{p}<0.05)$.

\begin{tabular}{rrrrrrrrrrr}
\hline \multicolumn{7}{c}{ Tratamientos (biofermentos de 500 g) } \\
\hline $\mathrm{N}^{\circ}$ & $\begin{array}{c}\text { B-Lac } \\
(\%)\end{array}$ & $\begin{array}{c}\text { Melaz } \\
\text { a (\%) }\end{array}$ & $\begin{array}{c}\text { Heces } \\
(\%)\end{array}$ & $\begin{array}{c}\text { Suero } \\
(\%)\end{array}$ & Día 0 & Día 1 & Día 2 & Día 3 & Día 4 & Día 5 \\
\hline 1 & 0 & 0 & 50.0 & 50.0 & 6.45 & 4.42 & 4.24 & 4.36 & 4.06 & $3.95^{\mathrm{a}}$ \\
2 & 0 & 5 & 47.5 & 47.5 & 6.35 & 4.47 & 4.23 & 4.29 & 3.76 & $3.78^{\text {abc }}$ \\
3 & 0 & 10 & 45.0 & 45.0 & 6.31 & 4.46 & 4.17 & 4.20 & 3.71 & $3.69^{\text {cd }}$ \\
4 & 0 & 15 & 42.5 & 42.5 & 6.22 & 4.44 & 4.13 & 4.26 & 3.74 & $3.75^{\text {bd }}$ \\
5 & 0 & 20 & 40.0 & 40.0 & 6.15 & 4.60 & 4.15 & 4.32 & 3.80 & $3.79^{\text {abc }}$ \\
6 & 5 & 0 & 47.5 & 47.5 & 6.40 & 4.38 & 4.10 & 4.24 & 3.83 & $3.90^{\text {ab }}$ \\
7 & 5 & 5 & 45.0 & 45.0 & 6.32 & 4.20 & 4.13 & 4.29 & 3.74 & $3.70^{\text {cd }}$ \\
8 & 5 & 10 & 42.5 & 42.5 & 6.22 & 4.15 & 4.00 & 4.16 & 3.67 & $3.66^{\text {cd }}$ \\
9 & 5 & 15 & 40.0 & 40.0 & 6.16 & 4.06 & 4.01 & 4.15 & 3.65 & $3.57^{\text {d }}$ \\
10 & 5 & 20 & 37.5 & 37.5 & 6.05 & 3.98 & 3.97 & 4.15 & 3.65 & $3.62^{\text {cd }}$ \\
11 & 10 & 0 & 45.0 & 45.0 & 6.32 & 4.26 & 4.07 & 4.23 & 3.77 & $3.77^{\text {abc }}$ \\
12 & 10 & 5 & 42.5 & 42.5 & 6.25 & 4.13 & 4.02 & 4.20 & 3.72 & $3.65^{\text {cd }}$ \\
13 & 10 & 10 & 40.0 & 40.0 & 6.13 & 4.16 & 4.06 & 4.20 & 3.70 & $3.68^{\text {cd }}$ \\
14 & 10 & 15 & 37.5 & 37.5 & 6.00 & 4.22 & 4.07 & 4.20 & 3.72 & $3.71^{\text {bcd }}$ \\
15 & 10 & 20 & 35.0 & 35.0 & 5.95 & 4.28 & 4.07 & 4.22 & 3.74 & $3.74^{\text {bcd }}$ \\
16 & 15 & 0 & 42.5 & 42.5 & 6.21 & 4.18 & 4.03 & 4.19 & 3.69 & $3.71^{\text {bcd }}$ \\
17 & 15 & 5 & 40.0 & 40.0 & 6.12 & 4.27 & 4.13 & 4.18 & 3.66 & $3.62^{\text {cd }}$ \\
18 & 15 & 10 & 37.5 & 37.5 & 6.05 & 4.07 & 4.02 & 4.19 & 3.70 & $3.67^{\text {cd }}$ \\
19 & 15 & 15 & 35.0 & 35.0 & 5.96 & 4.13 & 4.06 & 4.20 & 3.68 & $3.67^{\text {cd }}$ \\
20 & 15 & 20 & 32.5 & 32.5 & 5.83 & 4.21 & 4.04 & 4.22 & 3.72 & $3.65^{\text {cd }}$ \\
21 & 20 & 0 & 40.0 & 40.0 & 6.13 & 4.36 & 4.18 & 4.29 & 3.66 & $3.70^{\text {cd }}$ \\
22 & 20 & 5 & 37.5 & 37.5 & 6.06 & 4.03 & 4.01 & 4.18 & 3.67 & $3.62^{\text {cd }}$ \\
23 & 20 & 10 & 35.0 & 35.0 & 6.01 & 4.22 & 4.05 & 4.15 & 3.68 & $3.67^{\text {cd }}$ \\
24 & 20 & 15 & 32.5 & 32.5 & 5.91 & 4.17 & 4.04 & 4.18 & 3.71 & $3.68^{\text {cd }}$ \\
25 & 20 & 20 & 30.0 & 30.0 & 5.82 & 4.28 & 4.06 & 4.22 & 3.74 & $3.70^{\text {cd }}$ \\
\hline
\end{tabular}

*Distintas letras en la columna indican diferencia significativa entre tratamientos $(\mathrm{p}<0.05)$.

Tabla 7: ANOVA de dos factores.

\begin{tabular}{lcccccc}
\hline Fuente de variación & $\begin{array}{c}\text { Grados de } \\
\text { libertad }\end{array}$ & $\begin{array}{c}\text { Suma de } \\
\text { cuadrados }\end{array}$ & $\begin{array}{c}\text { Cuadrados } \\
\text { medios }\end{array}$ & \multicolumn{1}{c}{ Fal. $_{\text {cal }}$} & Ftab. & Significancia \\
\hline Tratamiento & 24 & 0.5156 & 0.0215 & 5.84 & 1.99 & $<0.0001^{* *}$ \\
Melaza & 4 & 0.1892 & 0.0473 & 12.87 & 2.56 & $<0.0001^{* *}$ \\
B-Lac & 4 & 0.1594 & 0.0399 & 10.84 & 2.56 & $<0.0001^{* *}$ \\
Melaza $X$ B-Lac & 16 & 0.1669 & 0.0104 & 2.84 & 1.81 & $0.0025^{* *}$ \\
Error & 50 & 0.1838 & 0.0037 & - & - & - \\
Total & 74 & 0.6994 & - & & & \\
\hline
\end{tabular}

** Alta significancia según la Prueba de Tukey $(\mathrm{p}<0.05)$.

Tabla 8: Contraste de medias de $\mathrm{pH}$ entre niveles de melaza y B-Lac.

\begin{tabular}{lccccc}
\hline \multicolumn{1}{c}{ Factor } & $0 \%$ & $5 \%$ & $10 \%$ & $15 \%$ & $20 \%$ \\
\hline B-Lac & $3.79^{\mathrm{a}}$ & $3.69^{\mathrm{b}}$ & $3.71^{\mathrm{b}}$ & $3.66^{\mathrm{b}}$ & $3.67^{\mathrm{b}}$ \\
Melaza & $3.80^{\mathrm{a}}$ & $3.67^{\mathrm{b}}$ & $3.67^{\mathrm{b}}$ & $3.68^{\mathrm{b}}$ & $3.70^{\mathrm{b}}$ \\
\hline * Distintas letras en una misma fila, indican diferencia significativa, según la Prueba \\
de Tukey (p<0.05).
\end{tabular}

${ }^{1}$ Investigador Asociado. Tesis de Maestría en Producción Animal. sigma_pgsl@hotmail.com

2 Departamento de Producción Animal de la Facultad de Zootecnia, Universidad Nacional Agraria La Molina. Av.

La Molina s/n. La Molina, Lima. Apartado Postal 12-056, Lima 12, Perú. wtrejocad@lamolina.edu.pe.

${ }^{3}$ Departamento Académico de Biología de la Facultad de Ciencias, Universidad Nacional Agraria La Molina. Av.

La Molina s/n. La Molina, Lima. Apartado Postal 12-056, Lima 12, Perú. jjm@lamolina.edu.pe. 